The Kidney. An Outline of Normal and Abnormal Structure and Function

By H. E. DE Wardener. Fourth Edition. Pp. 432, illustrated. Edinburgh and London: Churchill Livingstone, 1973. £5.50.

Since the third edition of this book in 1967 there have been important developments in the field of renal disease, notably the use of immunofluorescent techniques in the study of renal biopsy material and as an aid to the investigation of the immunological mechanisms involved in glomerular disease. There have been considerable advances in what is known about divalent cation and nitrogen metabolism in chronic renal failure, and in the handling by the kidney of sodium in health and disease.

The new edition of Professor de Wardener's book amply covers these advances to which the author has himself made so many important contributions. The book remains probably the best balanced and most readable of all texts on renal physiology and disease. It is balanced both in its views, content and style, which is in a large part owing to the fact that it is written by one author.

\section{Rehabilitation of the Hand}

By C. B. Wynn Parry. Third edition. Pp. 354, illustrated. London: Butterworths, 1973. $£ 9.00$.

The remarkably extensive area of representation of the hand in the cerebral cortex is perhaps the best indication of its importance in human life. Thus is explained the development of the original small volume on the techniques of rehabilita- tion of the injured hand, a seemingly small and specialized field, into the present edition which must be judged one of the few really worthwhile books available on rehabilitation in general. By including the management of fore-quarter amputation it may be said to have exceeded its brief a little, yet even this chapter is a logical enough extension of the consideration of the flail limb following brachial plexus avulsion.

The author's painstaking precision in electrodiagnosis is well known and has contributed greatly to the wider acceptance of electromyography as a valuable diagnostic tool. Here in a little over 20 pages will be found the answers to many of the everyday puzzles found in the EMG clinic. The sections on lively splints and on prostheses are likewise full of ingenuity and sound practical advice which is not to be had elsewhere except through personal apprenticeship. It is for this reason that the very high price of the book is so unfortunate. It will tend to prevent it coming into the hands of many who would value its contents more highly than its elegant production, particularly occupational therapists, physiotherapists and junior medical staff. As it is, physicians in rheumatology and rehabilitation must try to ensure its ready availability in their departments.

Particularly to be recommended is the chapter on the rheumatoid hand contributed by $\operatorname{Dr} D$. A. Brewerton and Mr A. W. F. Lettin which rightly emphasizes the benefits to the patient of joint management by physician and orthopaedic surgeon working closely together. The concluding chapter on resettlement further highlights the need for a team approach to ensure that the restored hand finds an appropriate task and its owner a place in society once again. 